\title{
The immediate upstream sequence of the mouse Ret gene controls tissue-specific expression in transgenic mice
}

\author{
PAOLA ZORDAN $^{1}$, SARA TAVELLA ${ }^{2}$, ANTONELLA BRIZZOLARA ${ }^{3}$, ROBERTA BITICCHI $^{2,5}$, \\ ISABELLA CECCHERINI $^{1}$, SILVIO GAROFALO ${ }^{2,5}$, ROBERTO RAVAZZOLO ${ }^{1,4}$ and RENATA BOCCIARDI ${ }^{1}$ \\ ${ }^{1}$ Laboratory of Molecular Genetics, Giannina Gaslini Institute, ${ }^{2}$ Department of Oncology, Biology and Genetics, \\ University of Genoa, ${ }^{3}$ Pediatric Surgery Division, Giannina Gaslini Institute, ${ }^{4}$ Department of \\ Pediatrics and CEBR, University of Genoa; ${ }^{5}$ National Institute for Cancer Research, Genoa, Italy
}

Received May 26, 2006; Accepted July 20, 2006

\begin{abstract}
The RET gene is tightly regulated at the transcriptional level during embryo development, however in vitro experiments in cultured cells have failed to clarify the molecular mechanism of cell-type specificity of RET promoter activity. Therefore, we have generated transgenic mice in which the LacZ reporter gene is controlled by murine Ret promoter sequences to clarify in an in vivo model how this transcriptional regulation is achieved. We describe here the results of reporter gene expression in mice in which the transgene contained 380- and 1962-bp sequence upstream of the ATG start codon, derived from the mouse Ret promoter region, fused to the $\beta$-galactosidase coding sequence. Transgenic mice showed well-defined patterns of B-galactosidase staining obtained with both transgenes, suggesting that they were able per se to direct the reporter gene expression in specific districts, such as cranial ganglia, dorsal root ganglia, the heart and the kidney, partially recapitulating the profile of the endogenous Ret gene. In particular, proper expression in the developing excretory system seemed quite significant when considering that the appropriate regulation was obtained with a very short, $380 \mathrm{bp}$, fragment of Ret 5 ' flanking sequence.
\end{abstract}

\section{Introduction}

Cell proliferation and differentiation are crucial processes during embryo development and are controlled by a complex network of regulated gene expression. This can occur at various levels starting from chromatin remodelling, through the modulation of the transcriptional process, to a variety of post-transcriptional modifications (1).

Correspondence to: Professor Roberto Ravazzolo, Laboratory of Molecular Genetics, Giannina Gaslini Institute, Largo G. Gaslini 5, 16147 Genoa, Italy

E-mail: rravazzo@unige.it

Key words: Ret, transcriptional regulation, promoter, transgenic mice, kidney development
The regulation of gene expression at the transcriptional level is one of the most important mechanisms of control in vertebrate embryos, and mainly depends on the specific interaction between transcription factors and their cognate recognition sequences of promoter and enhancer elements.

The $R E T$ proto-oncogene encodes a transmembrane receptor with tyrosine kinase (RTK) activity. So far, four specific ligands, glial cell line derived neurotrophic factor (GDNF), artemin (ARTN), neurturin (NRTN) and persephin (PSPN) with the corresponding phosphatidylinositol (GPI)linked ligand-binding subunits have been described as components of a multimeric complex in which RET is the pivotal transducer element $(2,3,4)$. The concerted expression of these genes during early stages of embryogenesis drives the migration and proliferation/differentiation of specific cell lineages deriving from neural crests leading to the development of enteric ganglia, thyroid C-cells, adrenal medulla, and the excretory system (5).

Accordingly, Ret knock-out mice (Ret $\left.{ }^{-/}\right)$have shown the absence of enteric ganglia throughout the digestive tract and renal agenesis or dysgenesis, and the lack of superior cervical ganglion (6,7). Moreover, targeted mutagenesis of Gdnf and Gdnf Receptor al (GFR 1 l) also leads to defective ureteric bud morphogenesis, thus causing kidney agenesis or dysgenesis $(8,9)$.

In humans, RET is involved in the genetic aetiology of several neurocristopathies, such as Hirschsprung disease, multiple endocrine neoplasia type $2 \mathrm{~A}$ and $2 \mathrm{~B}$, and both sporadic and familial isolated medullary thyroid carcinoma $(10,11)$.

The temporal and spatial pattern of expression of this gene during embryogenesis suggests that it is tightly regulated at the transcriptional level $(5,12)$ and so far several studies have been carried out to identify the molecular determinants of such an expression specificity. Comparison of the human and mouse promoter sequences shows a limited degree of identity at the nucleotide level. However, there is good conservation in terms of structure: absence of canonical consensus TATA or CAAT boxes, a high GC content with several GC boxes and putative Sp1 binding sites (13), which suggests a conserved mechanism of transcriptional control.

In vitro experiments showed that a restricted region of the human RET promoter is sufficient to drive reporter gene 
expression and that the SP1 transcription factor is the major activator of promoter activity $(14,15,16)$. It was also demonstrated that the RET promoter is responsive to the Pax 3 and Sox 10 transcription factors (17), and that its expression is influenced by epigenetic processes (18).

However, experiments in cultured cells failed to reproduce cell-type specificity of the RET promoter activity, consistent with the regulated spatio-temporal profile of the endogenous gene in tissues. This observation has emphasized the need to specifically generate animal models to clarify how the regulation of the RET gene transcription is achieved at the molecular level.

Lang et al (2000) reported the generation of transient transgenic mice carrying a 5.1-kb fragment from the human RET promoter driving the $\beta$-galactosidase ( $\beta$-gal) coding sequence as reporter gene. They found $B$-gal staining in the stomach and in the gut, where the endogenous gene is normally expressed. However, the observed staining pattern did not entirely encompass the endogenous profile, suggesting the lack of specific regulatory elements in the fragment used, and/or the existence of species-specific differences in the regulatory mechanisms (17).

Afterwards, Sukumaran et al described the analysis of transgenic mice carrying the LacZ gene under the control of four genomic fragments from the mouse Ret promoter (19). In that study, the main construct consisted of a sequence spanning $12 \mathrm{~kb}$ upstream of the ATG start codon from which three other constructs were derived by progressive deletion at the 5 ' end, thus obtaining fragments of $6 \mathrm{~kb}, 2 \mathrm{k} \mathrm{b}$ and $0.2 \mathrm{~kb}$, respectively. The authors described a modular organisation of the cis-acting elements controlling the Ret gene transcription: a distal region contained in the $12-\mathrm{kb}$ construct, reported as specific for gene expression in the primitive streak, in the lateral mesoderm and facial ganglia; a proximal region included in the $6 \mathrm{~kb}$-fragment directing Ret expression in the developing somatosensory system (19). Again, the pattern of the reporter gene did not recapitulate entirely the endogenous profile of Ret, as no staining was found in motorneurons, the enteric nervous system, autonomic ganglia and the developing urogenital system (19). Moreover, no ß-gal expression was detected in transgenic embryos carrying the two smallest fragments of 2 and $0.2 \mathrm{~kb}$.

Our recent work on the mouse Ret gene regulation has shown that a fragment as small as $380 \mathrm{bp}$ upstream of the ATG start codon was able to control reporter gene expression in transfected cell lines (20). To verify whether this promoter sequence was also able to function in an in vivo context, we generated transgenic mice for two genomic fragments, containing 380- and 1962-bp sequence upstream of the ATG start codon, derived from the mouse Ret promoter region, fused to the $B$-gal coding sequence as reporter gene.

We describe here the results of reporter gene expression in these transgenic mice which showed well-defined patterns of B-gal staining obtained with both transgenes, suggesting that they were able per se to direct the reporter gene expression in specific districts, partially recapitulating the profile of the endogenous Ret gene. In particular, proper expression of the reporter gene was observed in the developing excretory system, consistent with what is widely reported for the endogenous Ret. This is significant when considering that the appropriate regulation was obtained with a very short, 380 bp, fragment of Ret 5 ' flanking sequence.

\section{Materials and Methods}

Cloning the murine Ret promoter region. The 380-bp (BPr) and 1962-bp (Pr1.9) fragments from the mouse Ret promoter were obtained by PCR using specific sense and antisense primers: BPr-F GGTACCACACGCACCCAGCTCCGACC and BPr-R AGATCTAGGAGCAGGCGGGTCTCG; Pr1.9-F GTCCCGCCCATGCTATCTGG and Pr1.9-R AGGAGCA GGCGGGTCTCG. For the BPr fragment, forward primer carried the $K p n I$ restriction site, reverse primer carried the $B g l I I$ restriction site, suitable for direct subcloning in the same restriction sites of the $\mathrm{p} ß \mathrm{Gal}$ basic vector (Clontech). The PCR product corresponding to the Pr1.9 fragment was subcloned first in pCR2.1 TOPO vector (Invitrogen), then excised and subcloned into the $K p n \mathrm{I} / \mathrm{XhoI}$ restriction sites of the $\mathrm{p} ß \mathrm{Gal}$ basic vector. Both constructs were verified by restriction analysis and sequencing.

Transgene construction and generation of transgenic mice. Transgenes were prepared from the two (BPr and Pr1.9) constructs by double digestion with KpnI and SalI restriction enzymes to remove vector sequences. The transgenes to be microinjected consisted of the sequences under analysis (380 and $1962 \mathrm{bp}$ ), LacZ coding sequence and 3' poly-A structures which stabilize the construct (Fig. 1). Transgenes were gel purified and prepared for microinjection.

FVB strain females were hormone-stimulated to induce superovulation and then mated with stud mice. Fertilized eggs were recovered by oviduct dissection of the plugged donor females and conserved in a microdrop culture until the microinjection. Transgene DNA was microinjected into these eggs by targeting the large male pronucleus. Manipulated embryos were transferred into the oviduct of recipient females (CD1 strain) plugged with vasectomized males .

Pregnancies were either contunued until the delivery (1820 days after the egg reimplantation in recipient females) to obtain founders for a transgenic line, or terminated at specific stages of embryonic development to allow the transient analysis of transgenic mice.

All procedures were carried out according to the principles for the use and care of animals, in order to prevent pain or unnecessary suffering. Animals were properly controlled for their well being and health, were fed ad libitum, and when needed sacrified by $\mathrm{CO}_{2}$ administration.

Identification and selection of transgenic mice was achieved by PCR and Southern blot analysis on genomic DNA extracted from mice tails, in the case of founders, and from placenta, for embryos.

PCR amplification was perfomed with a sense oligonucleotide specific for the mouse Ret promoter (TR1F: 5'-CT CTCATCAGTACCGCAACC-3') and an antisense primer mapping on the $L a c Z$ coding sequence (TR1R: 5'-GCTCAG GTCAAATTCAGACGG-3').

$\beta$-galactosidase staining. Embryos harvested at the stage of interest were fixed for $30 \mathrm{~min}$ in $2 \%$ paraformaldehyde, $0.1 \mathrm{M}$ phosphate buffer, $\mathrm{pH} 7.4$, and $2 \mathrm{mM} \mathrm{MgCl}_{2}$, and washed 


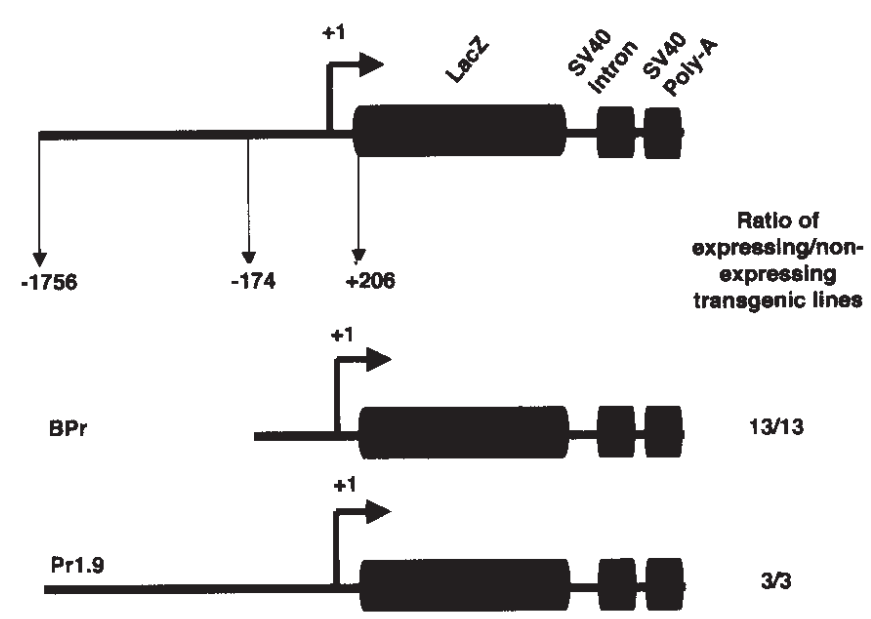

Figure 1 Schematic representation of the constructs used to generate transgenic mice (BPr and Pr1.9). LacZ, coding sequence for the Bgalactosidase reporter enzyme with the SV40 intron, UTR and poly-A sequences.

three times for $30 \mathrm{~min}$ in a washing solution containing $0.1 \mathrm{M}$ phosphate buffer $\mathrm{pH} 7.4,2 \mathrm{mM} \mathrm{MgCl}_{2}, 0.1 \%$ sodium deoxycholate and $0.2 \%$ Nonidet P-40. B-gal staining of the whole embryos was developed by an overnight incubation at $37^{\circ} \mathrm{C}$ in the washing solution with $1.0 \mathrm{mg} / \mathrm{ml} \mathrm{X}$-gal (5-bromo4-chloro-3-indolyl- $\beta$-D-galactoside, Roche), $5 \mathrm{mM}$ potassium ferricyanide, and $5 \mathrm{mM}$ potassium ferrocyanide. The embryos were then washed extensively, dehydrated in an increasing ethanol scale and then made diaphanous in cedar wood oil (Aldrich), before being photographed with a Nikon digital camera under a Nikon SMZ800 stereomicroscope.

Stage matched wild-type embryos were also collected and processed as described to be used as controls. Positive embryos for $\beta$-galactosidase staining were then cleared in xylene and embedded in paraffin to obtain sagittal and transverse sections $(30-\mu \mathrm{m})$, subsequently dewaxed and mounted with a coverslip to be analysed and photographed.

Histology and immunohistochemistry. For sections, wild-type embryos were fixed and dehydrated as described above, cleared in xylene and then embedded in paraffin. Sagittal (5$10-\mu \mathrm{m})$ cuts of embryos, obtained with a microtome, were dewaxed, rehydrated and boiled in citrate buffer $(10 \mathrm{mM}$, $\mathrm{pH}$ 6.0) to be prepared for immunohistochemistry experiments with an anti-Ret specific antibody to evaluate the expression of the endogenous gene. Endogenous peroxidase was blocked by $3 \% \mathrm{H}_{2} \mathrm{O}_{2}$ in phosphate-buffered saline (PBS) for $5 \mathrm{~min}$ at room temperature. After washing in PBS non-specific binding was blocked by $10 \%$ fetal calf serum (FCS; GibcoBRL) in PBS for $1 \mathrm{~h}$ at room temperature.

Sections were incubated overnight at $4{ }^{\circ} \mathrm{C}$ with the antiRet antibody (Ret C-19: sc-167; rabbit polyclonal IgG, $200 \mathrm{mg}$ / $\mathrm{ml}$; Santa Cruz) diluted 1:200 in 10\% FCS/PBS.

After washing, sections were incubated with the secondary antibody (goat anti-rabbit immunoglobulins, peroxidase conjugated; EnVision ${ }_{+}{ }^{\mathrm{TM}}$, Dako) for $1 \mathrm{~h}$ at room temperature. AEC (ammino-ethil-carbazole, Sigma) was used as chromogenic substrate for the enzymatic reaction (AEC, $30 \% \mathrm{H}_{2} \mathrm{O}_{2}$, sodium acetate $0.1 \mathrm{M}, \mathrm{pH}$ 5.2). Slides were finally mounted with coverslips.

\section{Results and discussion}

Generation of transgenic mice. To study the mechanisms regulating the cell-type specific expression of the Ret gene, we followed an in vivo approach based on the generation of transgenic mice carrying the $L a c Z$ reporter gene driven by two different genomic fragments of $380 \mathrm{bp}$ (Basal Promoter, BPr), and 1962 bp (Pr1.9), immediately upstream of the ATG start codon of the mouse Ret gene (Fig. 1), which we had already utilized in in vitro experiments. Our results had shown that the 380 bp sequence was able to control Ret gene expression in cultured cell lines (20). In P19 cells induced to neural differentiation, we found that Ret gene expression was also induced, and this correlated with a differential binding of $\mathrm{SP} 1 / \mathrm{SP} 3$ proteins to their recognition sites in this sequence. Since these data suggested that this small fragment might play a role in regulating tissue specificity of Ret expression, we decided to verify whether the very short regulatory sequence contained in the BPr transgene and the longer one contained in $\operatorname{Pr} 1.9$ were able to function in an in vivo context.

We obtained thirteen transgenic mice (two stable lines, A and $\mathrm{B}$, and eleven transient transgenic mice) carrying the $\mathrm{BPr}$ transgene, and three stable lines $(\alpha, \beta$, and $\delta$ ) for the Pr1.9, as assessed by PCR with oligonucleotides specifically designed to detect the presence of these transgenes. Embryos, either from stable lines or from transient experiments, were harvested at defined developmental stages and the pattern of $\beta$-gal staining was evaluated in whole embryos or in histological samples derived from such embryos.

All the transgenic mice obtained (13/13 and 3/3 for BPr and Pr1.9 transgene, respectively) developed clearly detectable and defined $\beta$-gal staining as exemplified in Fig. 2. The staining pattern displayed in the whole embryos demonstrated that both types of regulatory sequences were active in promoting gene expression and that reporter gene expression was found in districts known to be expressing the endogenous Ret gene in mice of corresponding embryonic stage.

This is in contrast with a previous study in which reporter gene expression was observed in transgenic mice carrying a Ret 5 ' flanking region of 12 and $6 \mathrm{~kb}$ respectively, fused to $\mathrm{LacZ}$, but not in deletion construct of 2 and $0.2 \mathrm{~kb}$ (19).

Cranial ganglia. Previous reports have shown that most cranial ganglia, including trigeminal and superior ganglia, are positive for Ret mRNA expression, in wt mouse embryos at the stage of 13.5-14.5 dpc (5).

Our 13.5-14.5 dpc transgenic embryos displayed expression of LacZ within glossopharyngeal (IX) ganglia in both BPr (6/13) and Pr1.9 (3/3) (Fig. 3A). Well detectable reporter gene expression was also found in the sensory epithelium of the cochlea (Fig. 3B) of all transgenic mice for both promoter fragments. This is in accordance with previous studies with rats and pigs, showing that the endogenous Ret is expressed in the epithelium of semicircular canals and is absent in the vestibul-ocochlear ganglion $(21,22,23)$.

Defined $\beta$-gal staining was detected in a subset of cells in the innervations of the tongue (3/13), the mandible branches of 
$\mathbf{A}$
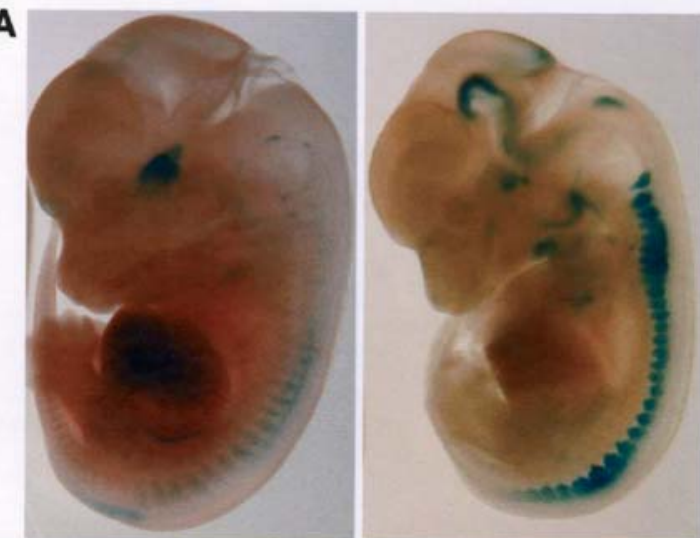

B
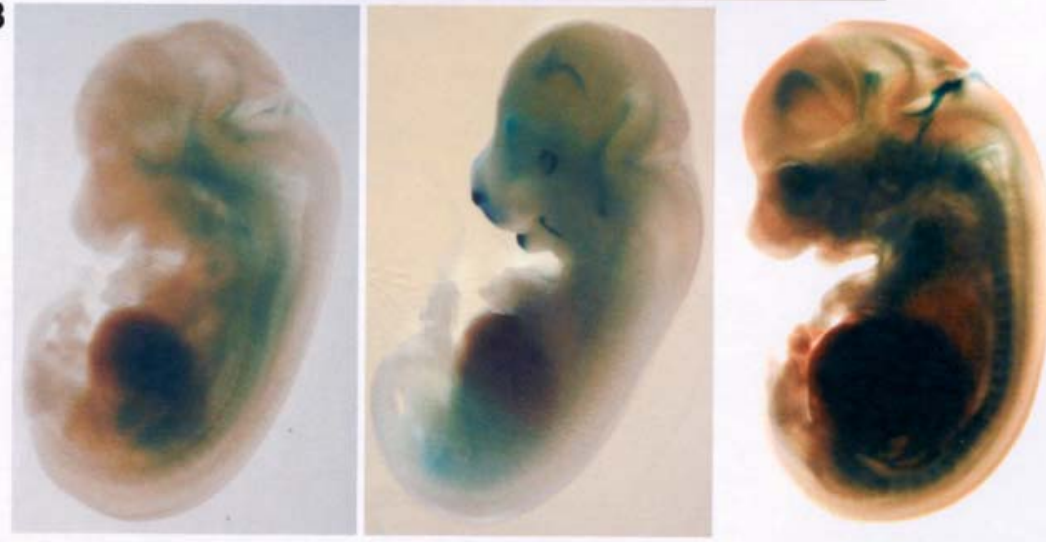

Figure 2. Tissue-specific expression of the LacZ reporter gene driven by the two genomic fragments from the mouse Ret promoter flanking region. Bgalactosidase expression pattern in whole embryos harvested at E13.5. Stable lines A and B (A), were generated with the BPr construct, whereas stable lines $\alpha, \beta$ and $\delta(B)$ were obtained with the Pr1.9 transgene.
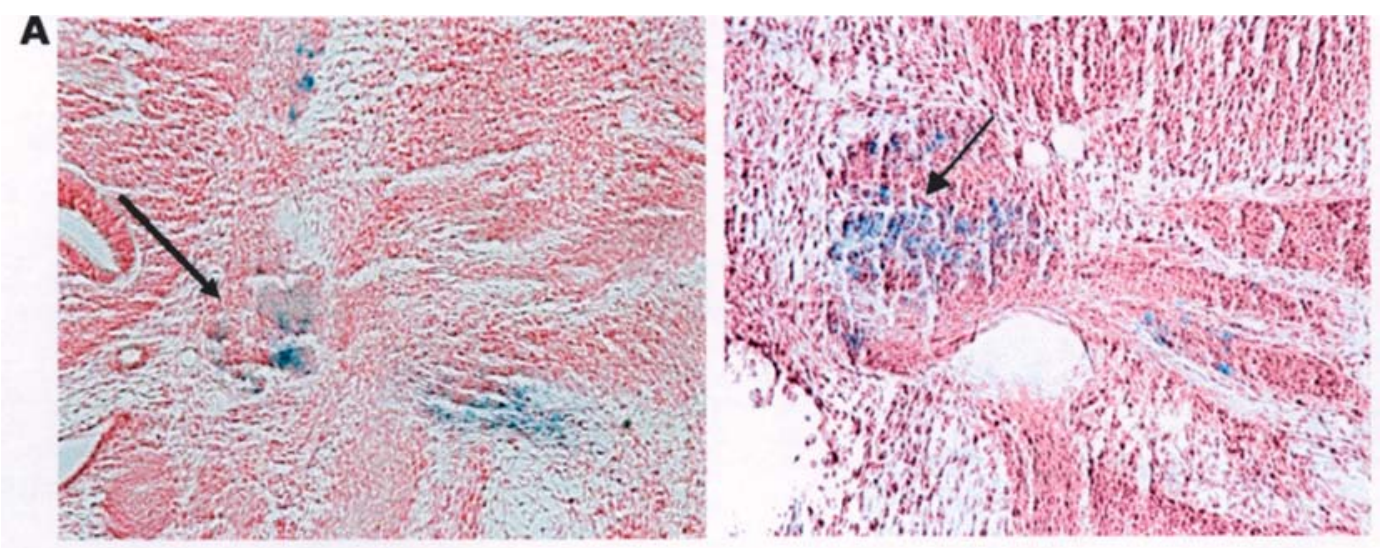

B

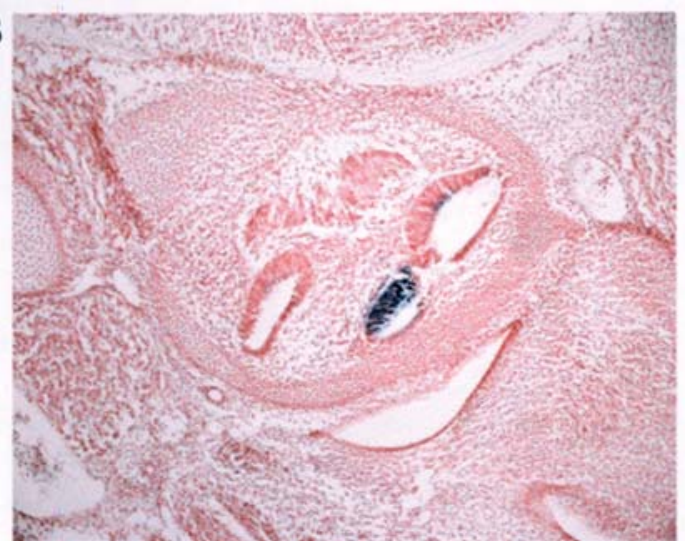

Figure 3. Histological sections of E13.5 transgenic mice showing the representative staining pattern of the LacZ reporter gene expression induced in the glossopharyngeal ganglion (A, arrows) and in the sensory epithelium of the cochlea (B) of transgenic mice for both promoter fragments. 

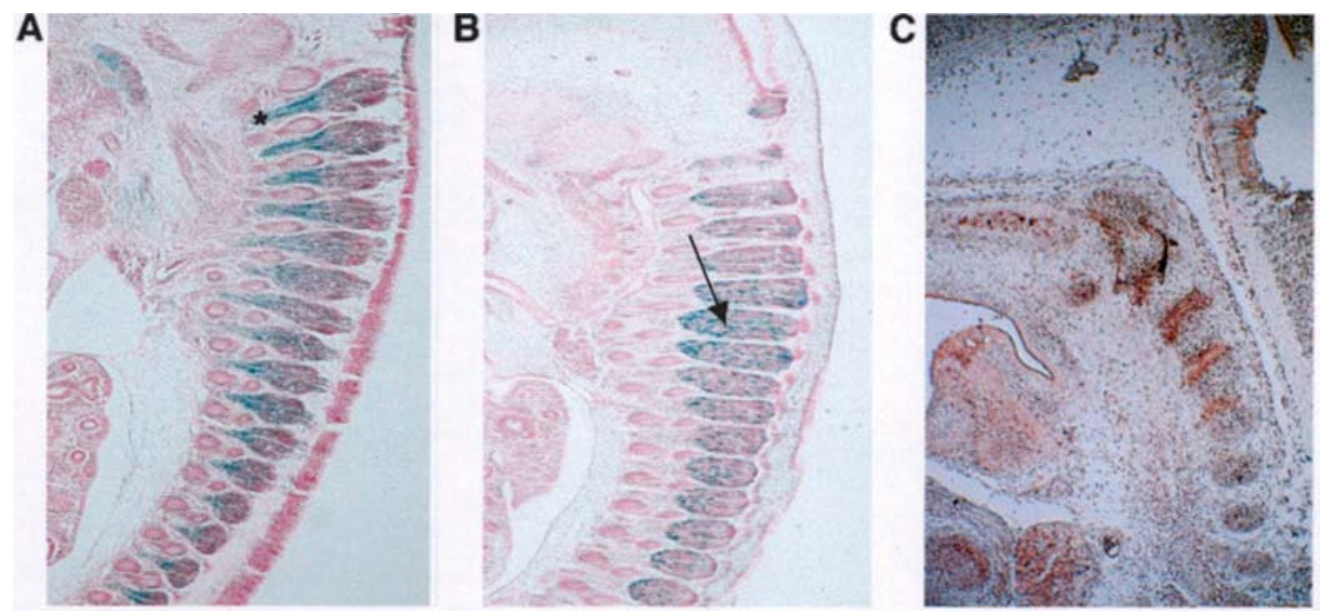

Figure 4. LacZ reporter gene expression in developing dorsal root ganglia. Parasagittal section of E13.5 transgenic embryos for the BPr construct. In the BPr transgenic line $\beta$-galactosidase staining is detectable in a subset of cells within the ganglia and in emerging nerve roots (A); in the BPr line B, the expression of the reporter gene is found only confined to a subset of neurons (B, arrow) and it is completely overlapping with the expression of the endogenous ret gene (C), as assessed by immunohistochemistry with specific anti-Ret antibodies.

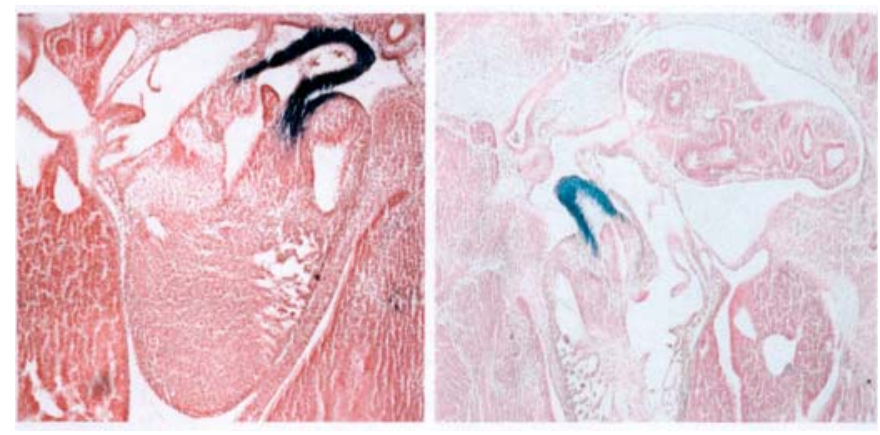

Figure 5. Histological sections of E13.5 embryos showing that the BPr transgene can induce $\beta$-galactosidase expression in the outflow tract of the developing heart.

the vagus (X) ganglia (4/13), and in the SCG (superior cranial ganglia) in 5/13 mice carrying the smallest BPr construct.

Moreover, the BPr transgenic mice also showed the reporter gene expression in the hair follicles of the vibrissae innervated by the maxillary branch of the trigeminal nerve (3/13). $\beta$-gal expression in the nucleus of the trigeminal nerve (V) was observed only in 1/13 BPr transgenic mice.

Dorsal root ganglia. In the two BPr stable lines, A and B, we found B-gal staining in a subset of cells within all the dorsal root ganglia (DRG). In BPr line A, the reporter gene was detected both in a subset of cells within the ganglia and in the emerging nerve roots (Fig. 4A). In BPr line B, LacZ staining was observed first within a few cells of DRG at the E10.5 dpc stage, and later, from 11.5 to 14.5 , this became an intense punctate signal in DRG of the entire embryo axis and was still absent from the emerging peripheral spinal nerves.

The expression of endogenous Ret in DRG is well documented in the literature and, in our case, the B-gal staining observed in the transgenic line B corresponded to the immunohistochemical staining observed in a control mouse at the same embryonic stage (Fig. 4B and C). However, this expression pattern was not observed in the other BPr transgenic mice nor in DRG from the Pr1.9 transgenic mice. This variable expression can be explained by strong dependence of both transgenes on position effect due to the random integration of constructs in the mouse genome.

As previously reported, Ret expression is found in cells derived from trunk neural crest. These cells also migrate ventrally in the sclerotome where they condense to form DRG. Later on, the expression shows a defined punctuate pattern suggesting that it is present in a restricted subtype of neurons and is absent in emerging roots (5). In late embryonic development and the early postnatal period Ret expression is confined to the large diameter, isolectin B4 (IB4+) binding DRG neurons, representing a subset of nociceptive sensory neurons. Later on in the postnatal life also the small and intermediate diameter IB4 ${ }^{+}$neurons become Ret positive $(19,24,25)$.

Several works have demonstrated that specific DRG neuron populations are sensitive to the trophic action of GDNF, on which they depend for their phenotypic maintenance and survival (24). However, the role of the GDNF/GFR $\alpha /$ Ret signalling in sensory neurons seems to be different in embryos compared to the postnatal life. During embryogenesis the activation of the Ret mediated pathway leads to the downregulation of several cytoskeletal and cell adhesion related genes, with a suppressive effect on neurite growth and/or branching (26). Therefore, it has been hypothesized that it may be involved in terminal innervation (sensory terminal innervation) (26). During late embryogenesis and postnatal development, GDNF/GFR $\alpha /$ Ret signalling exerts a potent anti-apoptotic effect on DRG neurons (27), supporting their survival in vitro and in dissected intact ganglia, and their rescue after axon injury (24).

Heart. Outside the nervous system, we found specific $\beta$-gal expression in the heart in $6 / 13 \mathrm{BPr}$ transgenic mice. The staining was confined to a specific region around the cardiac outflow tract (Fig. 5). This finding is in accordance with several lines of evidence showing that Ret is involved in the normal development of the heart, at the level of both 

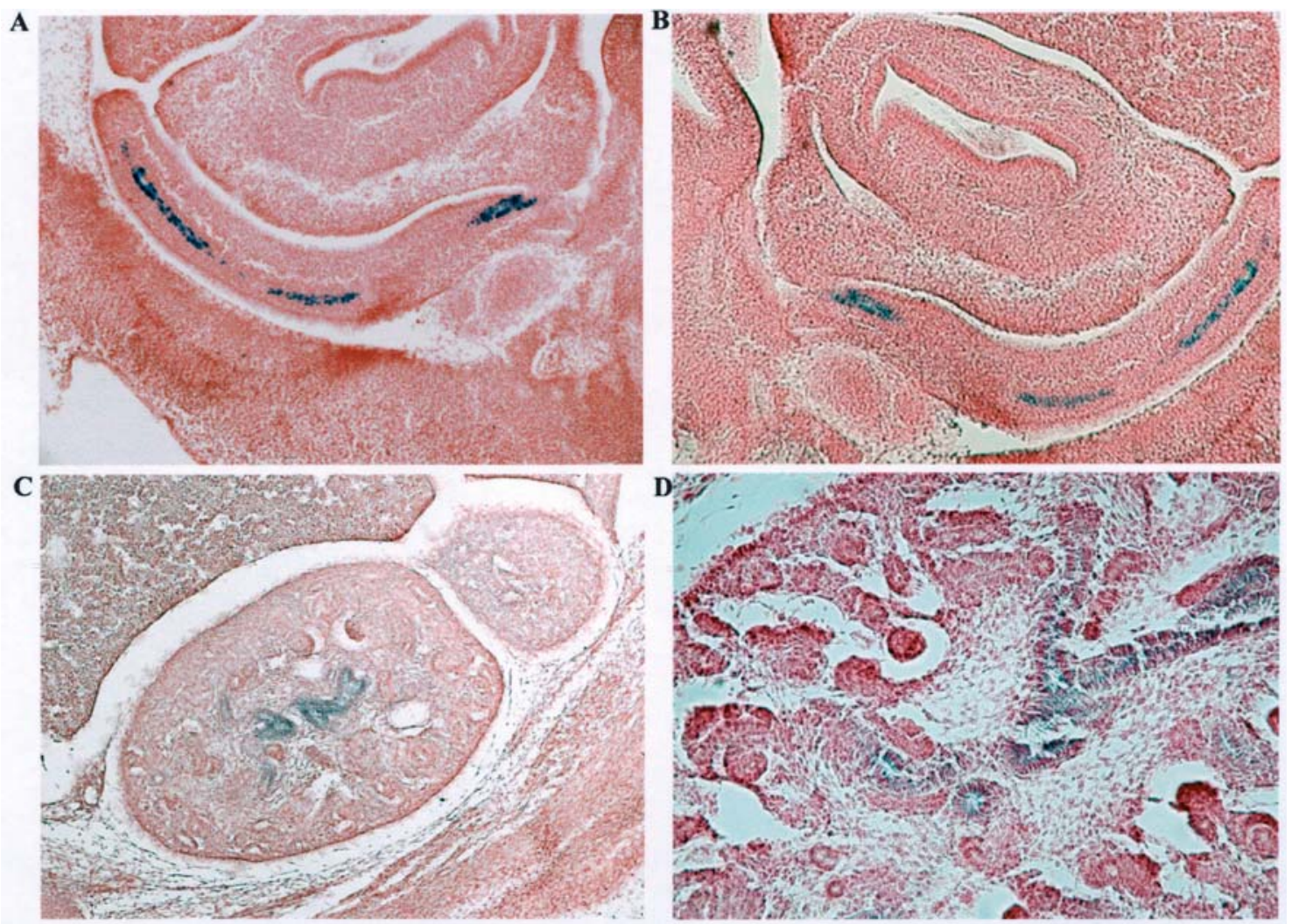

Figure 6. Both BPr and Pr1.9 transgenes can induce the LacZ reporter gene expression in the developing kidney. Parasagittal sections of E11.5 (A and B) and E13.5-14.5 (C and D) transgenic embryos showing the specific B-galactosidase staining pattern in the nephric duct (A and B) and in a restricted number of cells in the collecting ducts of metanephros (C and D).

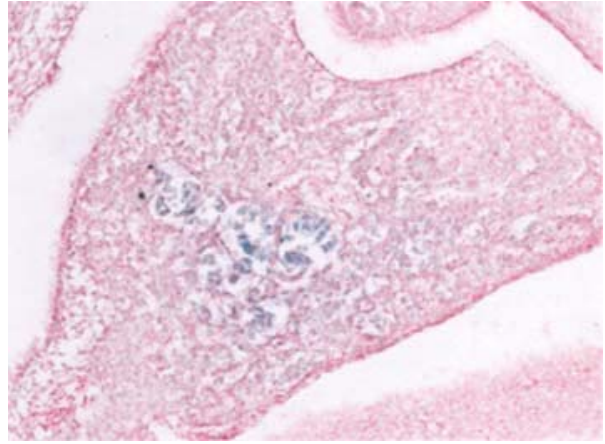

Figure 7. B-galactosidase staining within a subset of cells surrounding the pancreatic ducts in the pancreas primordium.

innervation and specification of cardiac structures. Ret $\mathrm{KO}$ mice have a reduced volume of cardiac ganglia and a defective innervation of the ventricular conduction system (28). The ablation of a premigratory cranial neural crest cell subpopulation perfomed in chick embryos led to malformation of the cardiac outflow tract and to septation defects. Moreover, myocardial development also was affected $(29,30)$. These data lead to the definition of a cardiac neural crest cell subpopulation which migrates between the distal end of the outflow tract and the pharyngeal endoderm, before invading the outflow tract itself and contributing to the formation of septal tissues $(31,32)$. The Ret gene, together with Mash-1, is one of the earliest markers appearing in the undifferentiated neural crest cells committed to migrate through the common cardinal vein and to differentiate in cardiac ganglion cells (32).

Interestingly, our results indicate that the Ret regulatory sequence contained in the very short BPr transgene is sensitive to regulation in the described heart district in a significant number of transgenic mice.

Kidney. All the transgenic mice showed B-gal staining (BPr 13/13 and Pr1.9 3/3) in the metanephric region. The expression pattern of the reporter gene in this region was well defined and completely overlapping for both BPr and Pr1.9 fragments. Sections of $10.5 \mathrm{dpc}$ embryos revealed the expression of the reporter gene in the nephric duct of the pro-mesonephros (Fig. 6A and B). Upon invasion of the metanephric mesenchyme (day 11-12.5) the ureteric bud began to branch to generate the collecting system. At these stages, we detected ß-gal staining in epithelial cells of the ureteric bud which was absent in the surrounding mesenchyme (Fig. 6C and D).

The glial cell line-derived neurotrophic factor (GDNF) and its receptors Ret and GFRa1 are essential positive regulators of primary ureteric budding and subsequent branching. GDNF is expressed by the metanephric mesenchyme and its receptors are expressed by the target tissues, the Wolffian duct and ureteric bud epithelium. A low level of GDNF expression is present in the uninduced metanephric mesenchyme and highly increased expression becomes evident in the cap condensates $(33,34)$. GDNF binds to a receptor complex consisting of Ret receptor tyrosine kinase and GDNF family 
receptor a1 $($ GFR $\alpha 1)$ in the Wolffian duct-derived epithelium. Binding results in the activation of Ret (2) which, in turn, regulates the expression of Wnt11 $(35,36)$, thus contributing to the regulation of ureteric branching (37). Ret is also involved in the regulation of the ureteric branching through another mechanism related to peritubular renal stroma. The stromal cells convert vitamin A to retinoic acid, which controls the expression of Ret in the ureteric bud tips by a yet unknown mechanism $(38,39)$. Our results suggest that cis regulatory elements contained in a very short fragment of Ret $5^{\prime}$ flanking sequence are able to control gene expression in the developing kidney, which addresses very precisely the search for transacting factors for which little is known in the pathway upstream of the GDNF receptors.

Enteric nervous system. As extensively documented, the Retmediated signalling pathway is important for the development of the enteric nervous system. However, we did not find LacZ expression within the neurons and glia that are organized into enteric ganglia distributed throughout the gut wall.

In transgenic mice carrying the Pr1.9 fragment we found defined B-gal staining within a subset of cells around the pancreatic ducts in the pancreatic primordium at a stage of 13.5 dpc (Pr1.9 3/3) (Fig. 7).

Only $1 / 13 \mathrm{BPr}$ (line B) transgenic mice showed LacZ expression within a subset of cells of the thyroid follicles in E13.5 embryos, where the endogenous gene is reported to be expressed (5).

In conclusion, all transgenic mice that we generated were able to express the reporter gene, although expression patterns were variable, particularly when considering cranial ganglia, dorsal root ganglia and the heart. Such variability is probably dependent on the effect of a transgene integration locus in the mouse genome which would affect the regulating potential of cis-acting elements in the cells of neuronal tissue.

Position effect seems to be ineffective on expression in the developing kidney, which might be explained by full responsiveness of cis-acting elements in the short promoter to their cognate transcription factors. To our knowledge, little is known about these factors and Ret transcriptional regulation, however, our data can be a useful basis to refine further search inside a 380 bp sequence.

\section{Acknowledgments}

This work was supported by an FIRB grant of the Italian Ministry of University to R.R. The secretarial assistance of Mrs. Loredana Velo is greatly acknowledged.

\section{References}

1. Villard J: Transcription regulation and human diseases. Swiss Med Wkly 134: 571-579, 2004.

2. Airaksinen MS and Saarma M: The GDNF family: signalling, biological functions and therapeutic value. Nat Rev Neurosci 3: 383-394, 2002.

3. Baloh RH, Enomoto H, Johnson Jr EM and Milbrandt J: The GDNF family ligands and receptors - implications for neural development. Curr Opin Neurobiol 10: 103-110, 2000.

4. Paratcha G, Ledda F and Ibanez CF: The neural cell adhesion molecule NCAM is an alternative signaling receptor for GDNF family ligands. Cell 113: 867-879, 2003.

5. Pachnis V, Mankoo B and Costantini F: Expression of the c-ret proto-oncogene during mouse embryogenesis. Development 119: 1005-1017, 1993.
6. Durbec PL, Larsson-Blomberg LB, Schuchardt A, Costantini F and Pachnis V: Common origin and developmental dependence on c-ret of subsets of enteric and sympathetic neuroblasts. Development 122: 349-358, 1996.

7. Schuchardt A, D'Agati V, Pachnis V and Costantini F: Renal agenesis and hypodysplasia in ret-k-mutant mice result from defects in ureteric bud development. Development 122: 1919-1929, 1996.

8. Enomoto H, Araki T, Jackman A, Heuckeroth RO, Snider WD, Johnson Jr EM and Milbrandt J: GFR alpha1-deficient mice have deficits in the enteric nervous system and kidneys. Neuron 21: 317-324, 1998.

9. Moore MW, Klein RD, Farinas I, Sauer H, Armanini M, Phillips H, Reichardt LF, Ryan AM, Carver-Moore K and Rosenthal A: Renal and neuronal abnormalities in mice lacking GDNF. Nature 382: 76-79, 1996.

10. Arighi E, Borrello MG and Sariola H: RET tyrosine kinase signaling in development and cancer. Cytokine Growth Factor Rev 16: 441-467, 2005.

11. Marx SJ: Molecular genetics of multiple endocrine neoplasia types 1 and 2. Nat Rev Cancer 5: 367-375, 2005

12. Tsuzuki T, Takahashi M, Asai N, Iwashita T, Matsuyama M and Asai J: Spatial and temporal expression of the ret protooncogene product in embryonic, infant and adult rat tissues. Oncogene 10: 191-198, 1995.

13. Panetta D, Yin L, Barale R, Romeo G, Ravazzolo R, Ceccherini I and Puliti A: Genomic organisation of the mouse Ret protooncogene. DNA Seq 11: 501-506, 2001.

14. Andrew SD, Delhanty PJ, Mulligan LM and Robinson BG: Sp1 and Sp3 transactivate the RET proto-oncogene promoter. Gene 256: 283-291, 2000 .

15. Patrone G, Puliti A, Bocciardi R, Ravazzolo R and Romeo G: Sequence and characterisation of the RET proto-oncogene $5^{\prime}$ flanking region: analysis of retinoic acid responsiveness at the transcriptional level. FEBS Lett 419: 76-82, 1997.

16. Patrone G, Puppo F, Cusano R, Scaranari M, Ceccherini I, Puliti A and Ravazzolo R: Nuclear run-on assay using biotin labeling, magnetic bead capture and analysis by fluorescence-based RTPCR. Biotechniques 29: 1012-1017, 2000.

17. Lang, D, Chen F, Milewski R, Li J, Lu MM and Epstein JA: Pax 3 is required for enteric ganglia formation and functions with Sox 10 to modulate expression of c-ret. J Clin Invest 106: 963-971, 2000.

18. Puppo F, Griseri P, Fanelli M, Schena F, Romeo G, Pelicci P, Ceccherini I, Ravazzolo R and Patrone G: Cell-line specific chromatin acetylation at the Sox 10-Pax3 enhancer site modulates the RET proto-oncogene expression. FEBS Lett 523: 123-127, 2002.

19. Sukumaran M, Waxman SG, Wood JN and Pachnis V: Flanking regulatory sequences of the locus encoding the murine GDNF receptor, c-ret, directs lac $\mathrm{Z}$ (beta-galactosidase) expression in developing somatosensory system. Dev Dyn 222: 389-402, 2001.

20. Zordan P, Ravazzolo R and Bocciardi R: A very short segment of the murine ret promoter contains elements sensitive to in vitro neural cell differentiation. Int J Mol Med 16: 325-331, 2005.

21. Ylikoski J, Pirvola U, Virkkala J, Suvanto P, Liang XQ, Magal E, Altschuler R, Miller JM and Saarma M: Guinea pig auditory neurons are protected by glial cell line-derived growth factor from degeneration after noise trauma. Hear Res 124: 17-26, 1998.

22. Hashino E, Johnson Jr EM, Milbrandt J, Shero M, Salvi RJ and Cohan CS: Multiple actions of neurturin correlate with spatiotemporal patterns of Ret expression in developing chick cranial ganglion neurons. J Neurosci 19: 8476-8486, 1999.

23. Stover T, Gong TL, Cho Y, Altschuler RA, Lomax MI: Expression of the GDNF family members and their receptors in the mature rat cochlea. Brain Res Mol Brain Res 76: 25-35, 2000.

24. Bennett DL, Michael GJ, Ramachandran N, Munson JB, Averill S, Yan Q, McMahon SB and Priestley JV: A distinct subgroup of small DRG cells express GDNF receptor components and GDNF is protective for these neurons after nerve injury. $J$ Neurosci 18: 3059-3072, 1998.

25. Molliver DC, Wright DE, Leitner ML, Parsadanian AS, Doster K, Wen D, Yan Q and Snider WD: IB4-binding DRG neurons switch from NGF to GDNF dependence in early postnatal life. Neuron 19: 849-861, 1997.

26. Linnarsson S, Mikaels A, Baudet $\mathrm{C}$ and Ernfors P: Activation by GDNF of a transcriptional program repressing neurite growth in dorsal root ganglia. Proc Natl Acad Sci USA 98: 14681-14686, 2001 
27. Baudet C, Mikaels A, Westphal H, Johansen J, Johansen TE and Ernfors P: Positive and negative interactions of GDNF, NTN and ART in developing sensory neuron subpopulations, and their collaboration with neurotrophins. Development 127: 4335-4344, 2000.

28. Hiltunen JO, Laurikainen A, Airaksinen MS and Saarma M: GDNF family receptors in the embryonic and postnatal rat heart and reduced cholinergic innervation in mice hearts lacking ret or GFRalpha2. Dev Dyn 219: 28-39, 2000.

29. Kirby ML, Gale TF and Stewart DE: Neural crest cells contribute to normal aorticopulmonary septation. Science 220: 1059-1061, 1983

30. Waldo K, Zdanowicz M, Burch J, Kumiski DH, Stadt HA, Godt RE, Creazzo TL and Kirby ML: A novel role for cardiac neural crest in heart development. J Clin Invest 103: 1499-1507, 1999.

31. Hutson MR and Kirby ML: Neural crest and cardiovascular development: a 20-year perspective. Birth Defects Res C Embryo Today 69: 2-13, 2003.

32. Schafer K, Neuhaus P, Kruse J and Braun T: The homeobox gene Lbx 1 specifies a subpopulation of cardiac neural crest necessary for normal heart development. Circ Res 92: 73-80, 2003.

33. Hellmich HL, Kos L, Cho ES, Mahon KA and Zimmer A: Embryonic expression of glial cell-line derived neurotrophic factor (GDNF) suggests multiple developmental roles in neural differentiation and epithelial-mesenchymal interactions. Mech Dev 54: 95-105, 1996.
34. Sainio K, Suvanto P. Davies J, Wartiovaara J, Wartiovaara K, Saarma M, Arumae U, Meng X, Lindahl M, Pachnis V and Sariola H: Glial-cell-line-derived neurotrophic factor is required for bud initiation from ureteric epithelium. Development 124: 4077-4087, 1997.

35. Ehrenfels CW, Carmillo PJ, Orozco O, Cate RL and Sanicola M: Perturbation of RET signaling in the embryonic kidney. Dev Genet 24: 263-272, 1999.

36. Pepicelli CV, Kispert A, Rowitch DH and McMahon AP GDNF induces branching and increased cell proliferation in the ureter of the mouse. Dev Biol 192: 193-198, 1997.

37. Majumdar A, Vainio S, Kispert A, McMahon J and McMahon AP: Wnt11 and Ret/Gdnf pathways cooperate in regulating ureteric branching during metanephric kidney development. Development 130: 3175-3185, 2003.

38. Batourina E, Gim S, Bello N, Shy M, Clagett-Dame M, Srinivas S, Costantini F and Mendelsohn C: Vitamin A controls epithelial/ mesenchymal interactions through Ret expression. Nat Genet 27: 74-78, 2001

39. Mendelsohn C, Batourina E, Fung, S, Gilbert T and Dodd J: Stromal cells mediate retinoid-dependent functions essential for renal development. Development 126: 1139-1148, 1999. 